\title{
WEB ACCESSIBILITY: A Digital Divide for Disabled People?
}

\author{
Alison Adam \\ David Kreps \\ University of Salford \\ Salford, U.K.
}

\begin{abstract}
The focus of this paper is Web accessibility for disabled people. Much of the Web remains inaccessible or difficult to access by people across a spectrum of disabilities and this may have serious implications for the potential use of the Web for increasing social inclusion. The topic of disabled Web access is introduced through a consideration of four discourses: digital divide, social construction of disability, legal, and Web accessibility. The lack of dialogue between these permits a passive liberal approach toward disability discrimination to prevail and this political position has become inscribed in widely used automatic software tools resulting in a reinforcement of the view that Web site accessibility approval may, in many cases, be deemed an empty shell.
\end{abstract}

\section{INTRODUCTION}

After more than a decade of development of the World Wide Web, despite the consolidation of Web accessibility standards, and despite the enactment of strong disability discrimination legislation in many Western countries, much of the Web remains inaccessible to disabled people. A recent UK study of accessibility of public Web sites put a figure of less than 20 percent on Web sites that meet even the most basic accessibility standards across a spectrum of disabilities including hearing, motor, and sight impairment (DRC 2004). Given the growing use of the Internet and WWW for information, education, social contact, and, increasingly, the provision of goods and services, a digital divide between disabled people and those whom society does not categorize as disabled, threatens to open up and grow. If much of the Web remains inaccessible to disabled people, this may severely limit the potential of the Web to act as a platform on which to build social inclusion. Our research question is, therefore: How can an understanding of the major discourses surrounding access to digital technologies by people with disabilities contribute to an understanding of why Web accessibility remains as a persistent problem?

Please use the following format when citing this chapter:

Adam, A., and Kreps, D., 2006, in IFIP International Federation for Information Processing, Volume 208, Social Inclusion: Societal and Organizational Implications for Information Systems, eds. Trauth, E., Howcroft, D., Butler, T., Fitzgerald, B., DeGross, J., (Boston: Springer), pp. 217-228. 
We argue that the complexities of Web accessibility are best understood and analyzed against a set of relevant discourses and that part of the reason for the obduracy of Web inaccessibility lies in crucial gaps in their engagement with each other. In the following sections we characterize the relevant discourses in terms of the digital divide discourse, the social construction of disability discourse focusing, for the present purposes, on World Wide Web access by the disabled, the legal discourse where we briefly describe the burdens that disability discrimination demands put on those who design Web sites and the Web accessibility discourse, including a brief history of the development of Web accessibility guidelines. There is a raft of such guidelines, the majority of which cannot be adequately checked by automatic software. We describe, briefly, three of the guidelines which are inadequately addressed by automatic checkers. Having described these discourses, the next section continues by making the argument that their lack of appropriate engagement, in certain places, leaves in place a traditional, often passive, liberal approach toward inclusion of the disabled in Web accessibility terms. Indeed, we make the stronger claim that such a political position can be seen as inscribed in automatic accessibility checking software, resulting in the accessibility stamp of approval which they confer being appropriately deemed an "empty shell" (i.e., the gap between espoused policy and actual practice resulting in an equality policy that is meaningless; Hoque and Noon 2004).

Our research methodology for arriving at a set of credible discourses was drawn from our personal histories as researchers in this and related areas. The first author has researched gender issues in IS and computer ethics with a knowledge of digital divide literature and social shaping of technology and was struck by the parallels between rhetoric on women's and disabled people's access to digital technology. The second author is an active Web developer with specialist technical knowledge of Web accessibility, whose own research into cyborgism had led him into the disability studies field, with a particular interest in disabled access to ICTs. It then became an exercise in piecing together our respective expertise and searching for literature where we felt there were gaps. Finally, we fashioned what we hope is a convincing model of the relevant discourses.

\section{DIGITAL DIVIDE DISCOURSE}

Although the concept of the digital divide or the postulated divide between the "information haves" and the "information have-nots" is relatively recent (probably first coined explicitly in 1995; Servon 2002, p. 24), it has rapidly become the peg on which to hang policy concerns ( Selwyn 2004; U.S. Department of Commerce 2000). A wider spectrum of writing, much of it academic, that postulates inequalities between those who have access to digital networked technologies and those who do not, has also developed (e.g., Loader 1998; Marshall et al. 2003; Norris 2001; Servon 2002). Following Selwyn (2004), we urge caution in embracing the term digital divide uncritically as there are conceptual limitations to the dichotomous conception of such a divide with its tendency to equate access with simplistic views of availability of technology. Accepting this caveat, the literature (i.e., policy and academic wings) offers a natural starting place to look for analyses of questions of disabled access to the Internet. However, the problem is not what the digital divide discourse says about disabled access, but what it does not say. Digital divide literature is surprisingly reticent about disability, with several of the 
major works in the field offering no discussion of disability (Loader 1998; Marshall et al. 2003; Norris 2001; Servon 2002) or only a passing mention of the form "gender, race, disability, etc."

Arguably, the focus of the digital divide has traditionally been the divide between rich and poor, between developed and developing countries. Yet gender, as an analytical device, has quickly become part of the repertoire of the digital divide (Cooper and Weaver 2003). It is also notable that otherwise sophisticated analyses include references to demographics such as age without considering disability as well (Selwyn 2004). Importantly, the relative absence, or at least late arrival, of disability in the academic wing of the digital divide is replicated in the policy wing. Disability was first considered only in the fourth of the U.S. Government's "Falling through the Net" reports of the mid to late 1990s (U.S. Department of Commerce 2000). What are the effects of leaving disability out in the cold?

As Selwyn (2004) argues, the explosion of interest in the digital divide is a central plank in the wider theme of social inclusion and exclusion in policy terms. Indeed, the shift toward a "socially inclusive" policy agenda in countries such as the United Kingdom, United States, and France is intimately entwined with notions of a digital divide. Selwyn (2002, p. 2) notes, "the convergence of these 'information society' and 'inclusive society' discourses into an ongoing debate over the potential of ICTs to either exacerbate or alleviate social exclusion." In the UK, "New Labour" has seized upon information and communications technologies (ICT) as the defining feature of modern citizenship. Nevertheless, within the digital divide discourse from the policy wing, critical discussion of how governments use technology to achieve social inclusion is somewhat thin. The prevailing view, at least within UK government policy, is of a clear divide between "connected" and "unconnected" citizens with the twin specter of the digital divide reinforcing existing social divides and creating a new digital version at the same time. As Selwyn (2002, p. 16) suggests, this follows the traditional "technologification" of areas such as education and health; social exclusion is next in line for the technical fix.

\section{SOCIAL CONSTRUCTION OF DISABILITY DISCOURSE AND WEB ACCESS}

Disability, itself, is clearly a contested term. As attitudes and understanding undergo changes toward more tolerance, so does acceptable terminology. Witness how the term crippled would now be universally regarded as offensive and that the term handicapped has more recently dropped from favor. It may be that disability as a term might have a limited span as it too conjures up a negative image of being measured against some norm of ability. The term differently abled is sometimes used and may be seen as preferable to disabled. Yet differently abled also implies being different to some norm of ability, so this term is not unproblematic. This signals the impossibility of ever achieving a neutral term - all carry the weight of political baggage. Understandably, individuals may resist being lumped together as a group and individual differences in circumstances make a huge difference to one's experience (see Trauth et al. 2004). Nevertheless, a key political strategy to press for change involves identifying oneself as a member of a group of people who have similar issues and concerns. Hence the identity politics of disability remain important. 
Such views are borne out by the tensions between the charity and medical models of disability which have hitherto prevailed (Fulcher 1989) and the newer models which challenge them. The medical model of disability emphasizes impairment as loss where the deficit is seen as belonging to the individual and where the presumed status and neutrality of professional medical judgement takes disability out of the political arena, emphasizing its supposed nature in terms of personal issues for medical judgement. The charity model sits alongside such a view in assuming that disabled individuals are to be the objects of pity and are requiring of charity rather than necessarily having a set of rights within the welfare state and within government policy (Goggin and Newell 2000). However a more radical approach is represented by the social, social barriers, or social construction of disability model, which emphasizes that locating disability in the individual as opposed to society is a political decision.

Available and appropriate technology, and how it is used, is an integral part of the social model of disability. Disability can be created by designing technology in such a way that some people cannot use it - a crucial point to which we return when considering Web site accessibility. As Goggin and Newell (2000, p. 128) note, "Disability can thus be viewed as a constructed socio-political space, which is determined by dominant norms, the values found in technological systems, and their social context." They argue that research has focused on analysis of particular types of impairment with the development of technical solutions specifically to address these, thus reflecting the dominant medical paradigm of disability (p. 132).

Counter to the social model, one might argue that a poor technological design could beget a short term impairment rather than a long term disability and that a handicap refers to the relationship between a person and their environment (Cook and Hussey 2001). However, if a technology persists in being unusable for years where it could readily be made usable, the distinction between short-term handicap and long-term impairment becomes blurred.

Understanding disability against the social model makes feasible a more focused challenge to the prevailing norms and power relations in society. In other words, the onus is on the wider society to make the Internet and Web accessible, rather than the onus being on the individual disabled person to acquire specific technical aids and/or to struggle with poorly designed and often inaccessible Web sites. The social or social construction model moves away from the idea of disability as individual deficit, locating it instead in terms of barriers in the social environment. "It is not bodily impairment as such, but rather social discrimination and biases that in fact produce "disability." (Guo et al. 2005, p. 51). Hence, one might argue that a poorly designed Web site could be regarded as creating disability.

\section{LEGAL DISCOURSE}

In several Western countries, including the United States, the United Kingdom, Australia, and countries in the European Union, legislation has been enacted to ensure that individuals are not discriminated against on the grounds of disability, gender, race, and, more recently (at least in the UK), age. In each of these regions where legislation is in force, to prevent discrimination against the disabled, this legislation is widely interpreted as mandating the use of accessibility techniques on the Web. Section 508 of the U.S. Rehabilitation Act (1973; updated in 1998) uniquely spells out specific 
requirements of federal Web sites to ensure their accessibility to disabled users, although this falls short of the benchmark accepted elsewhere and applies only to federal, and not private sector, Web sites.

In the UK, the Disability Discrimination Act (1995) came into force in phases over a period of almost 10 years. It is now unlawful to discriminate against disabled people by refusing them service, providing service on worse terms, or providing a lower standard of service. It also requires service providers to make reasonable adjustments to the way they provide their goods, facilities and services to make them accessible. The owner of any public facing Web site, public or private sector, is a "service provider" under the terms of the Act, and must therefore comply with the law (DRC 2002).

In Europe, the eEurope Actions Plan 2002 and 2005, followed by EU Council and EU Parliament resolutions (EU Parliament 2002), mandate accessibility standards for all public Web sites. European national legislation on disability discrimination as it relates to the provision of services, has also been interpreted as including services delivered electronically.

The chairman of the UK Disability Rights Commission, Bert Massie, however, states that, "the industry should be prepared for disabled people to use the law to make the Web a less hostile place" (DRC 2004). These are strong words; they explicitly urge disabled people to look to the law if their needs are not met.

\section{WEB ACCESSIBILITY DISCOURSE}

In this section we briefly consider how technical development of the Web, and attempts to regulate it, have contributed to the development of the Web accessibility discourse. We hope to clarify, briefly, three of the specific ways in which Web sites may be inaccessible to disabled people and to explain why automatic software checkers will not necessarily flag such problems.

Central to the Web accessibility movement is the World Wide Web Consortium (W3C), the body established by Berners-Lee in 1994 to try to marshal the phenomenal growth of the Web his mark-up language, HTML, has spawned. The exponential growth of the Web encouraged unregulated, complex, and cumbersome plug-ins and unwieldy new versions of HTML. In response to this, the $\mathrm{W} 3 \mathrm{C}$ began creating a new foundational language for the future of the Web: extensible mark-up language (XML). ${ }^{1}$

XML is at the heart of Berners-Lee's concept of the Semantic Web, and his wish, through the universal application of rigorously quality processed international standards for code languages, to see machines talking to one another on our behalf. Parallel with these developments, the W3C undertook an exercise entitled the Web Accessibility Initiative (WAI), which in 1999 published its Web Content Accessibility Guidelines (WCAG). As part of the initiative, new elements and attributes were introduced into the code to help make it more accessible to disabled people.

The WCAG provide a set of guidelines for creating Web pages that are accessible to all, regardless of sensory, physical, or cognitive ability. To provide Web developers with a graded approach to the implementation of accessibility, three levels have been

'HTML and XHTML Frequently Asked Questions from the W3C site, http://www.w3.org/MarkUp/2004/xhtml-faq. 
defined - Level A, Level AA, and Level AAA - which cover items on Web pages that must, should and may, respectively, be made accessible in order for individuals with disabilities to access content. Most governmental directives specify Level AA as the minimum requirement, although the U.S. Section 508 falls somewhat short of this. The EU Council and Parliamentary resolutions specify the W3C's Web accessibility standards, mandating compliance, Europe-wide, with WCAG Level AA (Council of Europe 2003).

The development of accessibility standards is part of the wider story of the development of the Web, a classic tale of free market profit making versus nonprofit making, nonproprietary regulation. In European terms, the pendulum has swung markedly toward regulation and standardization. Given the active approach that disability discrimination legislation requires, this would seem to be a very positive move toward achieving accessibility. The free market will not emphasize accessibility unless it is compelled to do so (although it may well be compelled if the exhortations of the $\mathrm{DRC}$ to the disabled community to test the legislation are anything to go by) or unless it sees compliance as profitable.

Either way, we cannot expect a World Wide Web modeled on the liberal values of the free market to produce an equitable and accessible space of its own accord. Accessibility and end to discrimination are not emergent properties of private profitmaking environments, quite the opposite (Winner 1997). Unfortunately positive moves toward standardization, with the potential for achievable accessibility standards are undermined both by the quantity of old style HTML sites still in existence, which are full of inconsistencies, and on a reliance on automatic checkers, which cannot possibly provide the necessary accessibility checks, as we now describe.

Automated approaches to checking Web pages against these guidelines have proliferated. Space permits a consideration of only three of the most common of these accessibility problems but a comprehensive list of the many accessibility traps may be found in Kreps and Adam (2006). Accessibility checking programs include A-Prompt (one of the better ones), Bobby (once the most popular one, now renamed WebExact), LIFT, and many others. The W3C maintain a list of such tools on their Web site, ${ }^{2}$ but are careful not to endorse any of them, and they do not provide their own software tool to check Web pages against their accessibility guidelines. The situation remains that the guidelines simply cannot be properly tested in an automated manner, and for many of them, only a human check is possible.

In the remainder of this section, we describe three typical problems where an automatic checker would pass a Web site as accessible while it remains inaccessible to many users. These examples relate (mainly) to visually impaired people. The findings of a major study (DRC 2004) showed visually impaired users having the most problems with accessibility. However, the report found that users with hearing and motor impairments also have many difficulties with Web accessibility. This acknowledges that there is a wide spectrum of accessibility issues which affect users differently. However, for reasons of space, we describe a group of visual accessibility issues here.

Ritchie and Blanck (2003, p. 19), in their survey of centers for independent living (CILs) service delivery via Web sites, highlight the absence of a text equivalent

${ }^{2}$ Evaluation, Repair, and Transformation Tools for Web Content Accessibility, http://www.w3.org/WAI/ER/existingtools.html. 
description of graphic images (ALT or alternative text errors), as the main error that caused the Web sites surveyed in their research to fail the Bobby software. ALT tags on images either being nonexistent or unhelpful is one of the key problems experienced by blind users in the UK's Disability Rights Commission survey of Web accessibility which involved a user panel of disabled people and which found less than 20 percent of public Web sites meeting the most basic accessibility level (DRC 2004, p. 29).

The provision of a text equivalent for every non-text element is one of the most basic W3C Web accessibility guidelines (WCAG 1.1). However it is eminently feasible for a Web site to pass automated software tools on this count and yet be providing a text description that is inadequate at best and meaningless at worst.

Visually impaired people use speech synthesis software that reads out the text on Web pages. Indeed, screen readers and voice browsers are perhaps the most commonly known assistive technologies used by disabled people to surf the Web. The IMG element of HTML is used to place an image on a Web page. The ALT attribute of this element was introduced in HTML 2, so that Web authors could provide a text equivalent for images. The UK's RNIB (Royal National Institute for the Blind) recommends using five words as the usual number required to produce a meaningful tag (e.g., ALT = "dog leaps for a stick"). Speech synthesis software then reads the ALT text back to the user. Unfortunately, automatic checkers will accept, for example, ALT = image.jpg in the code, as a valid ALT attribute. They cannot check whether the text supplied is actually meaningful.

Speech synthesis software enables visually impaired users to "skim" pages, in a similar way that sighted users "scan" pages. Such software reads out only the headings and subheadings, until a keypress stops the skimming process and the software reads out the paragraphs beneath the subheading selected. The HTML elements $<\mathrm{H} 1>$ to $<\mathrm{H} 5\rangle$ create headings and subheadings, and $<\mathrm{p}>$ denotes a paragraph. Automated software checkers can only detect the absence of $\langle\mathrm{H1}\rangle-\langle\mathrm{H} 5\rangle$ in code, and recommend a human check; they cannot detect when a heading or subheading has been placed in a $\langle\mathrm{p}\rangle$.

Forms on Web pages enable interaction for a wide range of purposes, from simple feedback to complex transactions. Speech synthesis software reading out the text beside form fields, so that visually impaired users know where to input their details, relies upon specific elements in the HTML code to ensure that the right labels are clearly associated with their corresponding input fields. A poorly coded form, while clear to sighted users, might easily lead a visually impaired user to type the expiry date of their card into the security id input field, their post code into the county field, and so on. An automated software checker can only check for the absence of the <label $>$ element and the $<$ for $>$ attribute in HTML forms. Human comprehension is required to correctly associate labels with their form controls, making the forms usable.

\section{THE NEGATIVE EFFECTS OF AUTOMATED APPROACHES}

The problem is not only that automated approaches to checking Web pages for accessibility are insufficient and unable to substitute for a human check. The existence and proliferation of such software has, in certain respects, actually hampered the global project of making the Web more accessible so it may be worse than an empty shell. 
Hoque and Noon (2004) coined this term to describe the effects of equality and diversity policies in the workplace, but the concept may be extended to apply to the inequalities relating to Web accessibility. They claim that, in many instances, equality policies are passive instruments which make little difference to the material experiences of workers subject to unequal conditions and practices. This is because the equality policies do not carry with them a recognition of the reasons inequalities occur and have no means of changing the inequality. The organization that has developed the policy believes it has done its job and has to do nothing more to achieve equality in the workplace. The equality and diversity policy is, therefore, an empty shell. Similarly, a "badge of accessibility," such as the approval of an automatic checker, may engender the view that nothing more needs be done to make a Web site accessible. The approval of the Web site is then an empty shell.

The Level A, Level AA, and Level AAA of the Web Accessibility Initiative has been used by a very popular tool called Bobby. Bobby was, and its replacement WebExact is, a very useful tool, insofar as it can quickly and effectively show how inaccessible a Web page is, but it is all too often misunderstood. Many organizationsincluding disability organizations - falsely believe that simply passing such tests will satisfy their Web accessibility obligations. For them, the measure of accessibility is whether or not their pages can attain the "Bobby Approved" icon. Therefore, the Bobby icon appeared to represent an achievable standard and a tangible, cost effective reward for efforts made toward Web accessibility. But it is really quite patronizing for disabled visitors to Web sites to be told that because it is a Bobby Approved page it is accessible to all. As we have seen above, where the alternative text on an image says "photol.jpg, 5100 bytes," the page would have successfully attain the Bobby Approved icon.

Interestingly, this tool has been subject to so much criticism on this count that it has finally, in 2005 , been consigned to history, replaced by a tool that makes fewer claims. ${ }^{3}$ The Bobby-approved icon, however, like the "tag soup" of old style HTML it often accompanies, will be adorning Web pages for a good while to come.

It has been a commonplace experience among Web developers tendering for work in the public sector in Europe, where the WAI Level AA benchmark is mandated for all Web sites, to find the specifications in the "invitation to tender" actually listing Bobby Approved as the required benchmark of accessibility. So, a tool that cannot possibly do the job of all the checks required is actually listed as the benchmark. If the authors of such tender documents are confused about what is required, then it is no wonder that, as the UK Disability Rights Commission reveal in their report, "The Web: Access and Inclusion for Disabled People-A Formal Investigation" (DRC 2004), 81 percent of the $1,000 \mathrm{Web}$ sites included in the investigation failed "to satisfy the most basic Web Accessibility Initiative category"-Level A.

Hence the Bobby icon, despite the best intentions of its designers who, in any case recommended that Web developers use Bobby only as a first step to ensure accessible Web page design, may be unintentionally promoting social exclusion.

${ }^{3}$ WebExact, http://Webxact.watchfire.com/. 


\section{DISSECTING THE DISCOURSES: IMPLICATIONS OF LIBERALISM AND TECHNOLOGICAL DETERMINISM}

Critics of liberalism (Adam 2005) note the problems of liberal discourse where there may be a general will toward a more equal and fairer society but where the deeper social and cultural structures of society, which are implicated in causing the inequality in the first place, are left unexplored. Sometimes a liberal agenda prevails because asking more searching questions raises the specter of substantial discrimination and oppression. This in turn, raises the question of who is doing the discriminating and oppressing and what advantages they are levering against other groups. The language of inequality and underrepresentation sounds more neutral and presents less of a challenge to the status quo than oppression and discrimination.

The liberal approach is manifest in, at least, the policy wing of the digital divide discourse where it is assumed that access to technology brings social inclusion without posing deeper questions of how this may come about and also without understanding the different types of exclusion-in other words, that there may be several digital divides. Not surprisingly, commentators (Adam 2005) have noted the alliance between liberalism and technological determinism. A liberal approach is one that accepts the objectivity of the world and the inevitability and desirability of technological development to the extent where technological access has historically been seen as the key to equality in contemporary policy discourse (Selwyn 2004). Such arguments are reproduced in the technologification to cure social ills rhetoric described by Selwyn (2002). Additionally, the paucity of discussion on disability within the (policy and academic) digital divide literature further entrenches the liberal position. This is partly because there simply has not been enough discussion and awareness, where it may be assumed that disabled access will "come out in the wash" when social inclusion is dealt with as a blanket phenomenon.

The approach of policy-oriented digital divide literature tends to be uncritical of technology and has paid insufficient attention to the details of disability. This contrasts with the view that sees disability as socially constructed even to the extent that technology may be seen as designed, albeit unintentionally, to create disability. This signals a major disjunction between these two discourses.

However, the legal discourse encapsulated, for instance, in the UK Disability Discrimination Act and surrounding discussion, does not sit comfortably with current technologification policy. In putting the onus on the service provider to make Web sites accessible, rather than on the disabled person to find a way of accessing what might be somewhat inaccessible sites, the law recognizes that the barrier lies not with the disability but with the technology and, by extension, those who create and design the technology. Additionally, the law recognizes that disabled people have rights. These two aspects are central planks of the social construction model. Therefore, we contend that UK law, at least implicitly, contains some elements of the social construction model.

The Web accessibility movement has largely concentrated on the technical aspects of the problem. Understandably, there are huge and sophisticated technical problems to be solved before Web accessibility can be achieved and much has already been accomplished by WAI and others. However Web accessibility discourse has, to date, 
overlapped fairly minimally with the digital divide, social construction, and legislative discourses, meaning that, so far, it has not been in the best position to take advantage of the more radical arguments of the social construction and legal discourses on barriers and rights, which could be used, very positively, to fuel its campaign.

Without a united voice, from the complete spectrum of relevant discourses from digital divide, through social construction and legal, on to Web accessibility, pressing for active rights of disabled people against constructed barriers to Web accessibility, a relatively passive liberal approach toward disabled access may yet prevail.

\section{THE PROBLEM WITH ACCESSIBILITY SOFTWARE: INSCRIBING A LIBERAL VIEW OR CREATING DISABILITY}

Finally, we argue that by relying on automated Web site accessibility software we are, in an important sense, designing into information systems the problematic liberal view of equality that we identify above, which results from the lack of engagement between the relevant discourses. Many such "accessibility approved" stamps of respectability found on the Web then fall into the category of empty shells. So the problems we highlight above are exacerbated by automatic software. This may be regarded as a form of inscription. As Akrich (1992) argues, particular political positions can be designed into or inscribed into technology. One legendary story of inscription in the design of technology is Winner's (1999) account of the road network on Long Island designed with low bridges so that buses could not pass underneath. Apparently this was a deliberate intention of the designer, to exclude poor and black people, who were more likely to be bus rather than car users, from parks. (Although the near mythical status of this story has since been fatally wounded by Steve Woolgar, who famously produced the appropriate Long Island bus timetable at a conference in 1999!)

In the present case, we are arguing that a liberal view of equality and access has been inscribed in the design of accessibility testing software. This is partly because disabled people have not been involved in the testing of Web sites and partly because the passive view of access prevails, where we need not think too much about what access means, rather we accept what the tool gives us. Also, following the social construction of disability discourse, we must consider that the proliferation of all of these inaccessible Web sites is creating disability. Hence, not just liberal politics, but even disability itself, can be regarded as inscribed in the design of this technology.

\section{CONCLUSION}

In this paper we have attempted to understand the exceedingly complex, somewhat troubled, and multifaceted picture of disabled access to the Web through a set of relevant discourses. We note the tension between the active approach demanded by disability discrimination legislation, supported by the social construction model and disabled rights discourse and the passive, liberal approach that is often taken toward 
inclusivity. The policy wing of the digital divide discourse has failed to dispel the latter in its lack of interest in disability and its enthusiasm for technologification. The Web accessibility movement, with its necessary concentration on technical aspects and standardization sees Web accessibility largely in technical terms and therefore is not availing itself of the more radical arguments of the social construction and legal movements which could be used to positive effect in its campaigns.

The liberal approach to disabled access, which tends to prevail in the teeth of the disjunctions in the relevant discourses, can be regarded as inscribed in software tools. This is reinforced by the inability of software to check for meaning so that humans are always required. Taking the popular Bobby icon as an example, we argue that having a badge of respectability can be counterproductive. If we want to get beyond passive and ineffective approaches to accessibility, given in any case that the legislation demands it, and pressure groups such as the UK Disability Rights Commission will actively press for testing the legislation, we should heed the calls of these groups. This must be coupled with a clear need for human intervention rather than automatic checking, to involve disabled people much more directly in the design and testing of Web sites. Only in this way can we expect to see genuine steps taken toward making the World Wide Web socially inclusive for disabled people.

\section{References}

Adam, A. Gender, Ethics and Information Technology, Basingstoke: Palgrave Macmillan, 2005.

Akrich, M. "The De-scription of Technical Objects," in W. E. Bijker and J. Law (eds.), Shaping Technology/ Building Society: Studies in Sociotechnical Change, Cambridge, MA: MIT Press, 1992, pp. 205-224.

Cook, A. M., and Hussey, S. Assistive Technologies: Principles and Practices, St Louis, MO: Mosby, 2001.

Cooper, J., and Weaver, K. D. Gender and Computers: Understanding the Digital Divide, Mahwah, NJ: Lawrence Erlbaum Associates, 2003

Council of Europe. "Council Resolution on the Implementation of the eEurope 200-5 Action Plan," Brussels, January 2003 (http://www.eu.int/information_society/eeurope/2005/doc/ all_about/resolution. doc).

DRC. "Disability Discrimination Act: Code of Practice," Disability Rights Commission, UK Parliament 2008_223, 2002 (http://www.drc-gb.org/thelaw/practice.asp).

DRC. "The Web: Access and Inclusion for Disabled People," Disability Rights Commission, London, 2004 (http://www.drc-gb.org/library/webaccessibility.asp).

EU Parliament. "European Parliament Resolution on the Commission Communication eEurope 2002: Accessibility of Public Web Sites and their Content," (COM(2001) 529-C50074/2002 -2002/2032(COS)), European Union, 2002 (http://europa.eu.int/information society/policy/accessibility/).

Fulcher, G. Disabling Policies?, London: Falmer Press, 1989.

Goggin, G., and Newell, C. "An End to Disabling Policies? Toward Enlightened Universal Service," The Information Society (16), 2000, pp. 127-133.

Guo, B., Bricout, J. C., and Huang, J. "A Common Open Space or a Digital Divide? A Social Model Perspective on the Online Disability Community in China," Disability \& Society (20:1), 2005, pp. 49-66.

Hoque, K., and Noon, M. "Equal Opportunities Policy and Practice in Britain: Evaluating the 'Empty Shell' Hypothesis," Work, Employment and Society (18:3), 2004, pp. 481-506. 
Kreps, D., and Adam, A. "Failing the Disabled Community? The Continuing Problem of Web Accessibility," in P. Zaphiris and S. Kurniawan (eds.), Human Computer Interaction Research in Web Design and Evaluation, Hershey, PA: Ideas Group, 2006 (forthcoming).

Loader, B. D. (ed.). Cyberspace Divide: Equality, Agency and Policy in the Information Society, London: Routledge, 1998

Marshall, S., Taylor, W., and You, X. (eds.). Closing the Digital Divide: Transforming Regional Economies and Communities with Information Technology, Westport, CT: Praeger, 2003.

Norris, P. Digital Divide: Civic Engagement, Information Poverty, and the Internet Worldwide, Cambridge, UK: Cambridge University Press, 2001.

Ritchie, H., and Blanck, P. "The Promise of the Internet for Disability: A Study of On-Line Services and Web Site Accessibility at Centers for Independent Living," Behavioral Sciences and the Law (21), 2003, pp. 5-26.

Selwyn, N. "'E-stablishing' an Inclusive Society? Technology, Social Exclusion and UK Government Policy Making," Journal of Social Policy (31:1), 2002, pp. 1-20.

Selwyn, N. "Reconsidering Political and Popular Understandings of the Digital Divide," New Media \& Society (6:3), 2004, pp. 341-362.

Servon, L. J. Bridging the Digital Divide: Technology, Community and Public Policy, Malden, MA: Blackwell, 2002.

Trauth, E. M., Quesenberry, J. L., and Morgan, A. J. "Understanding the Under Representation of Women in IT: Toward a Theory of Individual Differences," in M. Tanniru and S. Weisband (eds.), Proceedings of ACM SIGMIS'04, New York: ACM Press, 2004, pp. 114-119..

U.S. Department of Commerce. "Falling Through the Net: Toward Digital Inclusion," Washington, DC: National Telecommunications and Information Administration, 2000 (available online at http://www.ntia.doc.gov/ntiahome/fttn00/contents00.html).

Winner, $\mathrm{L}$. "Cyberlibertarian Myths and the Prospect for Community," ACM Computers and Society (27:3), 1997, pp. 14-19.

Winner, L. "Do Artefacts Have Politics?," in D. MacKenzie and J. Wajcman (eds.), The Social Shaping of Technology, Buckingham, UK: Open University Press, 1999, pp. 28-40.

\section{About the Authors}

Alison Adam is a professor of Information Systems and is currently Head of the Information Systems Institute at the University of Salford. Her research interests lie in critical information systems, gender and information systems, and computer ethics. Her recent book, Gender, Ethics and Information Technology, brings together these themes. Alison may be contacted at a.e.adam@salford.ac.uk.

David Kreps holds a BA(Hons) in Theatre and Arts Management, an MA in Cultural Studies, and a Ph.D. in the Sociology of Technology. David spent several years as a local government officer, running arts centres, and has been chairman of Kaos Theatre UK since 1997. He has been making Web sites since 1995, and is director of fourquarters IS Ltd. (http://www.fourquarters.biz). After several years lecturing part-time, David joined the Information Systems Institute at the University of Salford in January 2004. He has since worked on the creation of the eGovernment Master's program delivered from September 2004, and lectures in Information Society and World Wide Web development. David can be contacted at d.g.kreps@salford.ac.uk. 